\title{
Determination of Meticillin Resistance and Investigation of Antibiotic Susceptibility of Staphylococcus aureus Strains Isolated from Clinical Samples
}

öz

Metisiline dirençli Staphylococcus aureus (MRSA) suşları tedavi seçeneklerinin kısıtılığı ve infeksiyon kontrol önlemlerinin maliyeti nedeniyle tüm dünyada ciddi bir sağık sorunu haline gelmiştir. Bu çalışmanın amacı, çeșitli klinik örneklerden izole edilen Staphylococcus aureus suşlarının metisilin direncinin yıllar içindeki değişimini ve antibiyotik duyarlılıklarını belirlemektir. Çalısmaya Ağustos 2015-Aralık 2018 tarihleri arasında hastanemiz Mikrobiyoloji Laboratuvarında çeşitli klinik örneklerden elde edilen ve tekrar izolatı olmayan toplam 197 S.aureus suşu dâhil edilmiştir. Bakteri identifikasyonu için matriks aracılı lazer dezorbsiyon iyonizasyon uçus zamanlı kütle spektrometresi (MALDI-TOF) (VITEK-MS, bioMérieux, Fransa), antibiyotik duyarlıı̆ı̆ının belirlenmesinde VITEK 2 otomatize sistemi (bioMérieux, Fransa) kullanılmıştır. Suşların antibiyotik duyarılığı, 2015 senesi için Clinical and Laboratory Standards Institute (CLSI), 2016 ve sonrası için European Committee on Antimicrobial Susceptibility Testing (EUCAST) kriterlerine göre değerlendirilmiştir. S.aureus suşlarının \% 79'u servis, \% 21'i poliklinik hastalarından izole edilmistir. Üc yılda izole edilen toplam 197 S. aureus susunun 47'si (\% 24) metisilin direncli, 150'si (\% 76) metisilin duyarlı olarak tanımlanmıștır. Metisilin direnci 2016 yılında $\% 5.5,2017$ 'de \% 21.3 ve 2018 yılında \% 26.4 saptanmış ve direncin yıllar içinde giderek arttığı izlenmiştir. MRSA izolatları en sık yoğun bakım ünitesi'nden gelen örneklerden elde edilmiştir. Suşların hiçbirinde vankomisin ve linezolid direnci saptanmazken, bir MRSA izolatinda otomatize sistem ve gradivent test ile teikoplanin direnci tespit edilmiştir. Fusidik asitin duyarlıığı hem MSSA (\% 97) hem de MRSA suşlarında (\% 89) oldukça yüksek bulunmuştur. Sonuç olarak, çeşitli klinik örneklerden izole ettiğimiz S. aureus suşlarında vankomisin ve linezolid direncine rastlanmamıștır. Hastanemizde saptadı̆̆ımız metisilin direnci ülkemiz ortalama değerlerinde bulunmakla birlikte, yoğun bakım ünitesinde yatan hasta sayısının artmasına paralel olarak üc yıl içinde ciddi bir artıs göstermiştir. Bu yüzden enfeksiyon kontrolü ile ilgili daha fazla önlem alınmasının, uygun antibiyotiğin kullanımı açısından direnç profilinin belli aralıklarla takip edilmesinin ve her hastanenin kendi antibiyotik kullanım politikasını olușturmasının önemli olduğu düșüncesindeyiz.

Anahtar kelimeler: antibiyotik direnci, MRSA, MSSA, Staphylococcus aureus

ABSTRACT

Methicillin-resistant Staphylococcus aureus (MRSA) strains have become a serious health problem worldwide due to the limited treatment options and the cost of infection control measures. The aim of this study was to determine the antibiotic susceptibility and the change in methicillin resistance of S.aureus strains isolated from various clinical specimens over the years. A total of 197 S.aureus strains (non-recurrent) obtained from various clinical specimens in Üsküdar State Hospital Microbiology Laboratory between August 2015 and December 2018 were included in the study. Matrix-assisted laser desorption ionization-time of flight mass spectrometry (MALDI-TOF) (VITEK-MS, bioMérieux, France) was used to identify microorganisms. For antibiotic susceptibility tests (AST) VITEK 2 automated system (bioMérieux, France) was used. When the AST results were evaluated, Clinical and Laboratory Standards Institute (CLSI) breakpoints were used for the year 2015 and European Committee on Antimicrobial Susceptibility Testing (EUCAST) breakpoints were used for and after 2016. Of the S.aureus strains, $21 \%$ were isolated from outpatients and $79 \%$ from hospitalized patients. Of the 197 S. aureus strains isolated in three years, 47 (23\%) were identified as methicillin resistant (MRSA) and 150 (73\%) were identified as methicillin susceptible (MSSA). Methicillin resistance was $5.5 \%$ in 2016, $21.3 \%$ in 2017 and $26.4 \%$ in 2018, pointing to a significant increase over the years. MRSA isolates were most frequently detected in samples from the intensive care unit. While vancomycin and linezolid resistance was not detected in any of the strains, teicoplanin resistance was found in an MRSA isolate by automated system and gradient test. The susceptibility to fusidic acid was very high in both MSSA (97\%) and MRSA strains (89\%). In conclusion, vancomycin and linezolid resistance was not found in S. aureus strains isolated from various clinical specimens. Although methicillin resistance detected in our hospital is within the average values of our country, it has rised significantly within three years consistent with the increasing number of inpatients in intensive care unit.Therefore, we consider that it is important to take more precautions for infection control, to track resistance profiles periodically for the use of effective antibiotics and to establish each hospital's own antibiotic usage policy.

Keywords: antibiotic resistance, MRSA, MSSA, Staphylococcus aureus

Alındığı tarih: 14.06 .2019

Kabul tarihi: 01.08.2019

Yayın tarihi: 30.08 .2019

Neslihan Arıcı Üsküdar Devlet Hastanesi Mikrobiyoloji Laboratuvarı İstanbul - Türkiye

dr.neslihan.cicek@gmail.com ORCID: 0000-0003-4788-0044

S. Aksaray 0000-0002-0552-1337 T.C. Sağlık Bilimleri Üniversitesi Tıbbi Mikrobiyoloji Anabilim Dalı Istanbul - Türkiye 
N. Arıcı ve S. Aksaray, Klinik Örneklerden İzole Edilen Staphylococcus aureus Suşlarının Metisilin Direncinin Belirlenmesi ve Antibiyotik Duyarlılıklarının Araştırılması

\section{GiRiş}

Staphylococcus aureus toplum ve hastane kaynaklı infeksiyonların en önemli etkenlerinden olup, lokal ve sistemik birçok hastalığa sebep olabilir ${ }^{(10)}$. Başta deri ve yumuşak doku infeksiyonları olmak üzere osteomyelit, septik artrit, pnömoni, endokardit ve bakteriyemiye neden olabilen S.aureus, hastane infeksiyonu etkenleri arasında ilk sıralarda yer almaktadır. Metisilin dirençli S.aureus'un (MRSA) sebep olduğu enfeksiyonlar, hastanede yatış süresinin uzamasının yanında yüksek morbidite ve mortaliteyle de sonuçlanmaktadır ${ }^{(10)}$. MRSA suşları tedavi seçeneklerinin kısıtlılığı, tedavide kullanılan antibiyotikler ve infeksiyon kontrol önlemlerinin maliyeti nedeniyle tüm dünyada halen ciddi bir sağlık sorunudur ${ }^{(20)}$. Metisiline dirençli S.aureus suşları tüm beta-laktam grubu antibiyotiklere (beşinci kuşak sefalosporinler olan seftarolin ve seftobiprol hariç) dirençli olmakla birlikte makrolidler, linkozamidler, kinolonlar ve aminoglikozidlere de direnç gösterebilmektedir ${ }^{(17)}$. MRSA'ya bağlı infeksiyonların tedavisinde glikopeptid grubu antibiyotiklerin özellikle de vankomisinin sık kullanımı sonucunda, vankomisine orta düzeyde duyarlı ve dirençli suşlarının ortaya çıktığı bildirilmektedir ${ }^{(3)}$. Son yıllarda artış gösteren bu çoklu antibiyotik direnci, ciddi MRSA enfeksiyonlarında antimikrobiyal tedavi seçeneklerini kısıtlayabilecek boyutlara ulaşmıştır ${ }^{(18)}$. Bu yüzden antibiyotik direnç profillerinin düzenli olarak izlenmesi, ampirik tedavide seçilecek ilaçların belirlenmesi ve direnç gelişiminin önlenebilmesi açısından önemlidir. Bu çalışmada, üç yıllık süre içerisinde hastanemizde çeşitli klinik örneklerden izole edilen S.aureus suşlarının metisilin direncinin yıllar içerisindeki değişiminin incelenmesi ve hastanemize ait direnç profilinin belirlenmesi amaçlanmıştır.

\section{GEREÇ VE YÖNTEM}

Üsküdar Devlet Hastanesi Mikrobiyoloji Laboratuvarı'nda Ağustos 2015 - Aralık 2018 tarihleri arasında çeşitli klinik örneklerden toplam 283 S. aureus suşu izole edilmiştir. Aynı hastaya ait birden fazla izolat çıkarılmış ve toplam 197 suş ile çalışmaya devam edilmiştir. Ayaktan ve yatan hastalardan alınan örnekler kanlı, Eosin Methylene Blue (EMB) ve çikolata agar besiyerlerine ekilmiş, kan kültürleri BacT/Alert 3D (bioMérieux, Fransa) otomatize kan kültürü sisteminde değerlendirilmiştir. Bakteri identifikasyonu için matriks aracılı lazer dezorbsiyon iyonizasyon - uçuş zamanlı kütle spektrometresi (MALDI-TOF) (VITEK-MS, bioMérieux, France), antibiyotik duyarlılığının belirlenmesinde ise VITEK 2 otomatize sistemi (bioMérieux, Fransa) kullanılmıştır. Otomatize sistemle vankomisine ve teikoplanine dirençli veya orta duyarlı bulunan suşlar bir gradiyent test yöntemi olan E-test (bioMérieux, Fransa) ile de test edilmiştir. Kontrol suşu olarak S.aureus ATTC 25923 standart suşu kullanılmıştır. Suşların antibiyotik duyarlılığı 2015 senesi için Clinical Laboratory Standarts Institute (CLSI), 2016 ve sonrası için The European Committee on Antimicrobial Susceptibility Testing (EUCAST) kriterlerine göre değerlendirilmiştir. Duyarlııı sonuçları, EUCAST Ocak 2019 önerileri doğrultusunda S (standart dozda duyarlı), I (artmış dozda duyarlı) ve $\mathrm{R}$ (dirençli) olarak sınıflandırılmıştır. Değişiklik öncesinde "duyarlı olmayan" suşları belirtmek amacıyla I ve R kategorileri birlikte gruplandırılmaktayken, bu değişiklik sonrasında $\mathrm{S}$ ve I kategorileri ile duyarlı suşlar, R kategorisi ile dirençli suşlar belirtilmektedir(21). Toplam metisilin direncinin hesaplanmasında 2015 yılına ait son beş aylık veri dahil edilirken; yıllara göre dağılım istatistiğinde, tüm yılı yansıtmayacağı için bu veri değerlendirme dışı bırakılmış, 2016, 2017 ve 2018 yılı için metisilin direnci ayrı ayrı hesaplanmıştır.

\section{BULGULAR}

Toplam 197 S.aureus suşunun 176'sı (\% 88) servis, 21'i (\% 11) poliklinik hastalarından izole edilmiştir. Suşların 47'si (\% 24) metisilin dirençli, 150'si (\% 76) metisilin duyarlı olarak tanımlanmıştır. MRSA'ların en sık Yoğun Bakım Ünitesi (YBÜ)'nden (\% 72) gelen örneklerde ürediği görülmüştür (Tablo 1). MRSA suşları en sık trakeal aspirat (\% 55) kültürlerinden izole edilmiştir. Metisiline duyarlı 
Tablo 1. MSSA ve MRSA suşlarının servislere göre dağılımı [n(\%)].

\begin{tabular}{lccc}
\hline Servis & MSSA & MRSA & Toplam \\
\hline Yoğun Bakım Ünitesi & $73(68)$ & $34(32)$ & $107(100)$ \\
Dahili Birimler & $29(72)$ & $11(28)$ & $40(100)$ \\
Cerrahi Birimler & $48(96)$ & $2(4)$ & $50(100)$ \\
\hline Toplam & $150(76)$ & $47(24)$ & $197(100)$ \\
\hline
\end{tabular}

MSSA: Metisilin duyarlı S.aureus MRSA: Metisilin dirençli S.aureus

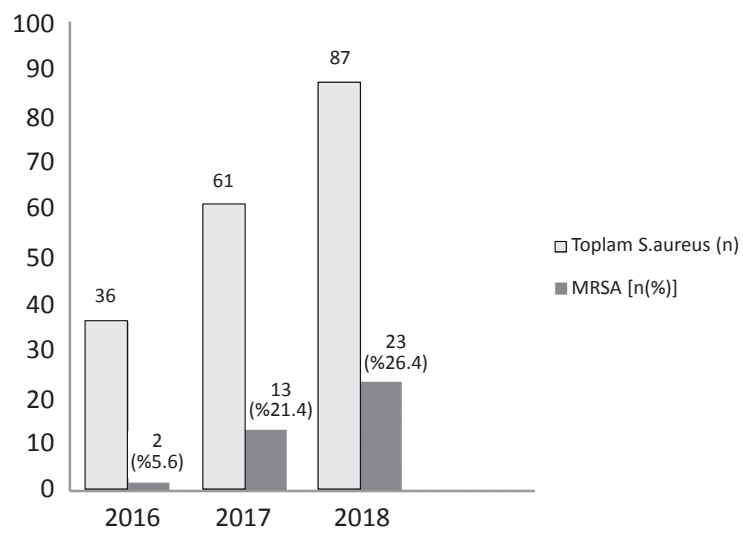

Grafik. Metisilin direncinin yıllar içindeki değişimi.

S.aureus (MSSA) ve MRSA izolatlarının örneklere göre dağılımı Tablo 2'de gösterilmiştir. Yıllara göre dağılım incelendiğinde, 2016 yılında 36 suşun ikisinde (\% 5.5), 2017'de 61 suşun 13'ünde (\% 21.3), 2018 yılında 87 suşun 23'ünde (\% 26.4) metisilin direnci saptanmış ve direncin yıllar içinde giderek arttığı belirlenmiştir (Grafik). Suşların hiçbirinde vankomisin ve linezolid direnci saptanmazken, bir MRSA izolatında otomatize sistem ve gradiyent test ile teikoplanin MiK değeri $4 \mu \mathrm{g} / \mathrm{ml}$ tespit edilmiştir. Bu suş için sıvı mikrodilüsyon doğrulama testi
Tablo 2. MSSA ve MRSA suşlarının örneklere göre dağılımı [n(\%)].

\begin{tabular}{lccc}
\hline Örnek & MSSA & MRSA & Toplam \\
\hline Trakeal Aspirat/Balgam & $61(70)$ & $26(30)$ & $87(100)$ \\
Yara & $43(86)$ & $7(14)$ & $50(100)$ \\
İdrar & $22(85)$ & $4(15)$ & $26(100)$ \\
Kan & $16(67)$ & $8(33)$ & $24(100)$ \\
Diğer (Vajen, Üretral) & $6(100)$ & $0(0)$ & $6(100)$ \\
Kateter & $2(50)$ & $2(50)$ & $4(100)$ \\
\hline Toplam & $150(76)$ & $47(24)$ & $197(100)$ \\
\hline
\end{tabular}

MSSA: Metisilin duyarlı S.aureus MRSA: Metisilin dirençli S.aureus

yapılamamıştır. Fusidik asitin etkinliği hem MSSA (\% 97) hem de MRSA suşlarında (\% 89) oldukça yüksek bulunmuştur. MRSA suşlarının toplam üç yıllık yıllık eritromisin, klindamisin, siprofloksasin, gentamisin direnç oranlarının MSSA suşlarının direnç oranlarına göre yüksek olduğu görülmüştür. MSSA ve MRSA suşlarının antibiyotik direnç oranları Tablo 3'te gösterilmiştir.

\section{TARTIŞMA}

Günümüzde S.aureus, tüm dünyada başlıca hastane kaynaklı patojenler arasında yer almaktadır. Özellikle de MRSA suşları, MSSA'lar ile karşılaştırıldığında daha uzun yatış süresi ve daha yüksek mortalite ile seyreden enfeksiyonlara yol açmaları sebebiyle önemli bir sorun olmaya devam etmektedir ${ }^{(10)}$

Küresel sürveyans verileri metisilin direncinin ülkeler, bölgeler, hastaneler ve hatta aynı hastanenin servisleri arasında değişkenlik gösterebildiğini ortaya

Tablo 3. MSSA ve MRSA suşlarının antibiyotik duyarlılıkları [n (\%)].

\begin{tabular}{|c|c|c|c|c|c|c|}
\hline & \multicolumn{3}{|c|}{ MSSA (150) } & \multicolumn{3}{|c|}{ MRSA (47) } \\
\hline & $\mathrm{S}$ & I & $\mathrm{R}$ & $\mathrm{S}$ & I & $\mathrm{R}$ \\
\hline Eritromisin & $98(66)$ & $26(17)$ & $26(17)$ & $13(33)$ & $4(3)$ & $30(64)$ \\
\hline Klindamisin & $125(83)$ & $0(0)$ & 25 (17) & $21(45)$ & $0(0)$ & $26(55)$ \\
\hline Gentamisin & $150(100)$ & $0(0)$ & $0(0)$ & $29(62)$ & $0(0)$ & $18(38)$ \\
\hline Siprofloksasin & $134(90)$ & $5(3)$ & $11(7)$ & $20(43)$ & $2(4)$ & $25(53)$ \\
\hline Fusidik Asit & $144(96)$ & $2(1)$ & $4(3)$ & $42(89)$ & $0(0)$ & $5(11)$ \\
\hline Tetrasiklin & 134 (89) & $0(0)$ & $16(11)$ & $15(32)$ & $0(0)$ & $32(68)$ \\
\hline Kotrimoksazol & $147(98)$ & $0(0)$ & $3(2)$ & $45(96)$ & $0(0)$ & $2(4)$ \\
\hline Vankomisin & $150(100)$ & $0(0)$ & $0(0)$ & 47 (100) & $0(0)$ & $0(0)$ \\
\hline Linezolid & 150 (100) & $0(0)$ & $0(0)$ & 47 (100) & $0(0)$ & $0(0)$ \\
\hline
\end{tabular}

R: Dirençli, S: Standart dozda duyarlı, I: Artmış dozda duyarlı 
N. Arıcı ve S. Aksaray, Klinik Örneklerden İzole Edilen Staphylococcus aureus Suşlarının Metisilin Direncinin Belirlenmesi ve Antibiyotik Duyarlılıklarının Araştırılması

koymuştur ${ }^{(10)}$. Avrupa'da yapılan sürveyans çalışmalarında batı ve güney Avrupa ülkelerinde MRSA oranı \% 32 ile \% 64 arasında izlenirken, İzlanda ve Hollanda'da bu oranın \% 2'nin altında olduğu bildirilmiştir(10). European Antimicrobial Resistance Surveillance Network (EARS-Net) 2015 yılı raporunda, ortalama MRSA oranlarının azaldığı, 2009 yılından bu yana ilk kez \% 16.8 olarak en düşük seviyesine ulaştığı bildirilmiştir. Ancak bu pozitif gelişmeye rağmen, MRSA oranlarının yüksek olduğu birkaç ülkede bu mikroorganizmaların önemli bir sağlık problemi olmaya devam ettiği vurgulanmıştır ${ }^{(6)}$.

Doğu Asya ülkelerinin katıldığı çok uluslu bir sürveyans çalışmasında hastane kaynaklı MRSA oranlarının ülkeler arasında \% 22 ile \% 86 arasında seyreden geniş bir aralıkta olduğu saptanmıştır(16). Amerika'da da yaklaşık 2000 hastanenin yer aldığı benzer bir çalışmada hastane kökenli MRSA oranının servisin türü ve enfeksiyonun yerine göre $\% 43$ ile $\% 58$ arasında değiştiği vurgulanmıştır ${ }^{(14)}$.

Ülkemiz Ulusal Antimikrobiyal Direnç Sürveyans Sistemi'nin (UAMDSS) 55 laboratuvarın katılımıyla gerçekleştirdiği sürveyans verilerine göre invaziv S.aureus izolatlarında (kan ve beyin omurilik sIVISI) MRSA oranı 2011, 2012, 2013, 2014-2015 ve 2016 yıllarında sırasıyla \% 31.5, \% 25, \% 26.9, \% 27 ve \% 23.6 olarak belirlenmiştir ${ }^{(23)}$. Buna ek olarak ülkemizde son yıllarda yapılan güncel çalışmalar incelediğinde metisilin direncinin \% 12 ile \% 48 arasında değiştiği görülmektedir ${ }^{(1,2,5,11,13,15,17,18,20,24,25)}$. Şen ve ark. ${ }^{(17)} 6317$ adet S.aureus suşunu içeren geniş kapsamlı çalışmalarında metisilin direncini \% 12.4, Telli ve ark. ${ }^{(20)} \%$ 15.3, Yüksekkaya ve ark. ${ }^{(26)} \% 17.9$ bulmuşlardır. Şirin ve ark. ${ }^{(18)}$ yaptıkları çalışmada, 1442 S.aureus suşunda metisilin direncinin dört yıllık süre içinde giderek azaldığını ve ortalama değerinin \% 15 olduğunu saptamışlardır. Rağbetli ve ark. ${ }^{(13)}$ 2009-2014 yılları arasında izole ettikleri 1116 S. aureus ile yaptıkları çalışmada metisilin direncinin yıllar içinde azalarak \% 30'dan \% 20'ye düştüğünü bildirmişlerdir. Ancak bu düşük oranların yanında daha yüksek direnç oranlarının saptandığı çalışmalar da mevcuttur. Doğan ve ark. ${ }^{(5)}$ metisilin direncini $\% 37.3$, Sipahi ve ark. ${ }^{(15)} \%$ 48.4, Nazik ve ark. ${ }^{(11)}$ ise
\% 48 olarak bulmuştur. Bizim çalışmamızda \% 23.8 olarak tespit ettiğimiz MRSA oranı ülkemizde yapılan çalışmaların bir kısmı ve UAMDSS oranlarıyla uyumludur. Ancak genel olarak ülke çapında gözlenen azalma eğilimi ile karşılaştırıldığında, direncin üç yıl içinde dramatik bir şekilde \% 5.5'ten \% 26'ya yükselmiş olması endişe vericidir. YBÜ'nde antibiyotiklere dirençli mikroorganizmalarla meydana gelen enfeksiyonların artışına; hastalığın şiddeti, YВÜ'lerinde kullanılan aletler, uygulanan invaziv girişimler, yetersiz enfeksiyon kontrolü ve çok ilaçlı ampirik tedavi uygulamaları gibi faktörler etki etmektedir( ${ }^{(4)}$. Nazik ve ark. ${ }^{(11)}$ ile Şen ve ark. ${ }^{(17)}$ çalışmalarında MRSA oranlarının yoğun bakım ünitelerinde diğer kliniklerden anlamlı derecede daha fazla olduğunu tespit etmişlerdir. Yine Zencir ve ark. ${ }^{(27)}$ MRSA üreyen örneklerin \% $60.8^{\prime}$ inin, Yüksekkaya ve ark. ${ }^{(26)} \% 48$ 'inin yoğun bakım ünitelerinden gönderildiğini bildirmişlerdir. Hastanemiz YBÜ'ndeki yatak sayısı 2016, 2017 ve 2018 yılları için sırasıyla 10, 23 ve 31 olarak tescillenmiştir. Üç yıl içinde yatak sayısının üç katına çıkmasının ve izole edilen MRSA'ların $\% 72$ 'sinin (47 izolatın $35^{\prime}$ i) bu üniteden gelmiş olmasının bu artışın en önemli sebebi olduğunu düşünmekteyiz. Yurtdışında ve ülkemizde YBÜ'lerindeki MRSA oranlarını inceleyen çalışmalarda ${ }^{(8,9)}$ yüksek bulunan değerlere benzer şekilde, YBÜ'nden izole ettiğimiz S.aureus'larda MRSA oranının \% 32 olarak yüksek saptanması da göz önüne alındığında metisilin direncindeki bu yükseliş anlaşılabilmektedir. Bu artışın önüne geçmek için mikroorganizmaların çapraz bulaş ve yayılmasının engellenmesi ve düzenli yapılmakta olan personel eğitimlerinde, etkinliğin arttırıımasına yönelik çalışmaların hayata geçirilmesi gerekmektedir. Bu sayede yoğun enfeksiyon kontrol önlemleri ile birlikte (el hijyeni, temas izolasyonu) direnç oranlarında genel bir azalma sağlamanın mümkün olacağını düşünmekteyiz.

Metisilin direncinin yaygınlaşmasıyla birlikte MRSA'ya bağlı invaziv enfeksiyonu olan hastaların tedavisinde vankomisin de sıklıkla kullanılmaktadır. Ancak bu yoğun kullanım sonucunda vankomisine orta düzeyde duyarlı ve dirençli S.aureus suşlarının ortaya çıktı̆̆ı bildirilmektedir(3,10). Ülkemizde yapılan 
çeşitli çalışmalarda ve UAMDSS sürveyans verilerinde S.aureus suşlarında vankomisin direncine rastlanmamıştır ${ }^{(1,5,11,13,15,17-20,23-27)}$. Biz de çalışmamızda bu verilerle uyumlu olarak vankomisin dirençli bir suş saptamadık. Bir diğer glikopeptid olan teikoplanin, vankomisine benzer etki spektrumunda, yan etkisi az olduğu için vankomisine alternatif olarak sıklıkla tercih edilen bir antibiyotiktir (27). Ülkemize ait birçok çalışmada ${ }^{(1,5,11,13,15,17,18,20,23-27)}$ S.aureus'larda teikoplanin direncine rastlanmamıştır. Bizim çalışmamızda otomatize sistemle dirençli bulunan bir MRSA izolatı E-test yöntemiyle de çalışılmış ve dirençli (MiK: 4 mg/ $\mathrm{ml)}$ bulunmuştur. Ancak EUCAST, gradiyent test yöntemi ile elde edilen minimal inhibitör konsantrasyon (MiK) değerlerinin sIVı mikrodilüsyon yöntemi ile bulunan MiK değerlerinden daha yüksek çıktığını belirterek, glikopeptid direncinin belirlenmesinde gradiyent testini önermemektedir(22). $\mathrm{Bu}$ nedenle otomatize sistem ve gradiyent test yöntemi ile dirençli bulduğumuz söz konusu izolatta teknik imkansızlıklar sebebiyle sıvı mikrodilüsyon çalışamamış ve referans laboratuvara gönderememiş olmamız bu çalışmanın kısıtııı̆ını oluşturmaktadır.

Linezolid, özellikle MRSA kaynaklı cilt ve yumuşak doku, toplum kökenli ve hastane kökenli pnömoni infeksiyonlarının tedavisinde glikopeptidlere alternatif olarak kullanılabilecek oksazolidinon grubu bir antibiyotiktir( ${ }^{(1)}$. Amerika'da yapılan geniş çaplı bir sürveyans çalışmasında MSSA'larda linezolid direncine rastlanmazken MRSA'larda \% 0.1 oranında direnç tespit edilmiştir( ${ }^{(7)}$. EARS-Net 2015 raporunda Avrupa ülkelerinde de benzer şekilde S.aureus'larda linezolid direnci \% 0.1 olarak bildirilmiştir ${ }^{(6)}$. UAMDSS'nin 2011 yılına ait raporunda bildirilen \% 2.3 linezolid direnci dışında, diğer raporlarında, ülkemizde yapılan çalışmalarda ve bizim çalışmamızda da linezolide karşı direnç saptanmamıştır ${ }^{(1,5,11,13,15,17,18,20,23-27)}$.

Florokinolonlar stafilokok enfeksiyonlarında sık kullanılan antibiyotikler arasındadır. Ülkemizdeki literatüre bakıldığında MRSA suşları için siprofloksasin direnci \% 44-92, MSSA suşları için \% 4-35 arasında değişmektedir ${ }^{(1,17,18,24)}$. Çalışmamızda siprofloksasin direnci benzer şekilde MRSA suşlarında \% 53, MSSA suşlarında \% 7 olarak tespit edilmiştir. Siprofloksasine "artmış dozda duyarlı" (I) oranı MRSA ve MSSA izolatları için sırasıyla \% 3 ve \% 4 olarak bulunmuştur.

S.aureus suşlarında gentamisin direnci ile ilgili çalışmalarda, Çalık ve ark. ${ }^{(2)}$ bu oranı MSSA için \% 6.4, MRSA için \% 3 olarak, Şirin ve ark. ${ }^{(18)}$ ise MSSA ve MRSA için sırasıyla \% 2.6 ve \% 45.5 olarak bulmuşlardır. Özel ve ark. ${ }^{12)}$ izole ettikleri MSSA suşlarında gentamisin direncine rastlamazken MRSA'larda bu oranı \% 25 olarak belirtmişlerdir. Çalışmamızda da benzer şekilde metisilin duyarlı suşlar içinde gentamisine direnç tespit edilmemiş, MRSA'larda \% 35 oranında direnç saptanmıştır.

Makrolid ve linkozamid grubu antibiyotikler hem MSSA hem de MRSA'ların sebep olduğu deri ve yumuşak doku enfeksiyonlarının tedavisinde, ayrıca penisilin alerjisi olan hastalarda kullanılmaktadır(24). Ülkemizde yapılan çalışmalarda MSSA suşlarında eritromisin ve klindamisin direnci sırasıyla \% 10-41 ve \% 1.4-34 arasında, MRSA suşlarında ise daha yüksek olarak sırasıyla \% 42-84 ve \% 38-62.5 arasında değişmektedir ${ }^{2}$ $, 5,12,17,18,24,26)$. Çalışmamızda ülkemiz verileriyle uyumlu olarak MSSA suşlarında eritromisin ve klindamisin direnci sırasıyla \% 17 ve \% 17, MRSA suşlarında ise sırasıyla \% 64 ve \% 55 olarak bulunmuştur. Eritromisin için MSSA suşlarında "artmış dozda duyarlı" (I) oranı $\% 17, M^{\prime} A^{\prime}$ larda ise $\% 3$ olarak tespit edilmiştir.

S.aureus infeksiyonlarının tedavisinde tercih edilebilecek diğer bir ilaç olan kotrimoksazolün direnç yüzdeleri ülkemizde yapılan farklı çalışmalarda MSSA için \% 1.5-32, MRSA için \% 10-66 arasında bildirilmiştir ${ }^{(2,5,12,17,18,26)}$. Çalışmamızda direnç oranları MSSA izolatlarında \% 2, MRSA izolatlarında ise \% 4 olarak tespit edilmiştir. Özellikle MRSA izolatlarında saptanan \% 96 oranındaki yüksek duyarlılık yüzdesi diğer çalışmalarla karşılaştırıldığında dikkat çekici bulunmuştur. Bu veriler ışığında yaşamsal risk taşımayan S.aureus infeksiyonlarının ampirik tedavisinde kotrimoksazol alternatif bir antibiyotik olarak düşünülebilir.

Fusidik asit, S. aureus'ların etken olduğu özellikle deri, yumuşak doku, kemikve eklem enfeksiyonlarında glikopeptidlere alternatif olarak kullanılabilen bir antibiyotiktir(2). Ülkemizde yapılan çalışmalarda, fusidik asit direnci MSSA izolatları için \% 4-12, 
N. Arıcı ve S. Aksaray, Klinik Örneklerden İzole Edilen Staphylococcus aureus Suşlarının Metisilin Direncinin Belirlenmesi ve Antibiyotik Duyarlılıklarının Araştırılması

MRSA için \% 8-25 arasında bildirilmiştir ${ }^{(2,12,17,18,24)}$. Çalışmamızda izole ettiğimiz MSSA ve MRSA suşlarında fusidik asit direnci sırasıyla \% 3 ve \% 11 olarak bulunmuştur. Diğer çalışmalarda olduğu gibi çalışmamızda da S.aureus suşlarında genel olarak fusidik asit direnç oranının düşük olduğu gözlenmiştir. $\mathrm{Bu}$ yüzden, özellikle MRSA enfeksiyonlarında glikopeptid direncinin önlenmesi açısından fusidik asit iyi bir alternatif olarak değerlendirilebilir.

S.aureus izolatlarında metisilin direncinin belirlenmesinde $\operatorname{mec} A / \operatorname{mec} C$ genlerinin saptanması altın standart olarak kabul edilmektedir ${ }^{(10)}$. İzole ettiğimiz suşlarda metisilin direncinin yalnızca otomatize sistemle belirlenmiş olması çalışmamızın bir kısıtlılığı olarak düşünülebilir.

Sonuç olarak, çeşitli klinik örneklerden izole ettiğimiz S.aureus suşlarında vankomisin ve linezolid direncine rastlanmamış olup, metisilin direnci ülkemiz ortalama değerlerinde bulunmuştur. Ancak, hastanelerde çoklu dirence sahip mikroroganizmaların en çok izole edildiği birim olan YBÜ’nde yatan hasta sayımızın üç yıl içinde üç kat kadar artmasıyla birlikte metisilin direnci de ciddi bir artış göstermiştir. Bu yüzden enfeksiyon kontrolü ile ilgili daha fazla önlem alınmasının, etkin uygun antibiyotiğin kullanımı açısından direnç profilinin belli aralıklarla takip edilmesinin ve her hastanenin kendi antibiyotik kullanım politikasını oluşturmasının önemli olduğu düşüncesindeyiz.

Teşekkür: Bakteri identifikasyon ve duyarlılık çalışmalarındaki katkılarından dolayı Kamu Hastaneler Başkanlığı-2'ye bağlı Merkez Laboratuvar-2 Mikrobiyoloji Bölümü’nde görevli tüm uzman doktor ve laboratuvar teknisyenlerine teşekkür ederiz.

Çıkar Çatışması: Yazarlar tarafından herhangi bir çıkar çatışması bildirilmemiştir.

Conflict of Interest: No conflict of interest was declared by the authors.

\section{KAYNAKLAR}

1. Coşkun MV, Alper Y, Uyanık MH, Yazgı H. Sensitivity of methicillin-resistant Staphylococcus aureus strains to fusidic acid and other non- $\beta$-lactam antibiotics. Klimik Derg. 2019;32(1):52-6. https://doi.org/10.5152/kd.2019.12

2. Calık Z, Karamese M, Acar O. Prevalence and antimicrobial-resistance of Staphylococcus aureus Isolated from blood culture in university hospital, Turkey. Glob J Infect Dis Clin Res. 2015;1(1):10-3.

3. Çıkman A, Aydın M, Gülhan B, et al. Metisiline dirençli Staphylococcus aureus izolatlarının antibiyotik direncive azalmışvankomisin duyarlılığının araştırılması: çok merkezli bir çalışma. Mikrobiyol Bul. 2015;49(2):240-8. https://doi.org/10.5578/mb.9230

4. Çıragil P. Ülkemizde yoğun bakım ünitelerinde antimikrobiyal direnç sorunu. Türk Mikrobiyol Cem Derg. 2016;46(3):97-104.

5. Doğan M, Feyzioğlu B, Baykan M. On yıllık dönemde S.aureus suşlarının antibiyotik direnç durumundaki değişim. Abant Med J. 2014;3(3):237-41. https://doi.org/10.5505/abantmedj.2014.74946

6. European Centre for Disease Prevention and Control. Antimicrobial resistance surveillance in Europe 2015. Annual Report of the European Antimicrobial Resistance Surveillance Network (EARS-Net). Stockholm: ECDC; (2017). doi 10.2900/6928.

7. Flamm RK, Mendes RE, Hogan PA, Streit JM, Ross JE, Jones RN. Linezolid Surveillance Results for the United States (LEADER Surveillance Program 2014). Antimicrob Agents Chemother. 2016;60(4):2273-80. https://doi.org/10.1128/AAC.02803-15

8. Göktaş U, Yaman G, Karahocagil MK ve ark. Anestezi yoğun bakım ünitesinde hastane enfeksiyonu etkenleri ve direnç profilinin değerlendirilmesi. J Turk Soc Intens Care. 2010;8(1):13-7.

9. Ippolito G, Leone S, Lauria FN, Nicastri E, Wenzel RP. Methicillin-resistant Staphylococcus aureus: the superbug. Int J Infect Dis. 2010;14(Suppl 4):S7-11. https://doi.org/10.1016/j.ijid.2010.05.003

10. Lakhundi $S$, Zhang K. Methicillin resistant Staphylococcus aureus: molecular characterization, evolution and epidemiology. Clin Microbiol Rev. 2018;31(4):e00020-18. https://doi.org/10.1128/CMR.00020-18

11. Nazik S, Cingöz E, Şahin AR, Güler S. Kan kültürlerinden izole edilen Staphylococcus aureus suşlarında metisilin direncinin yıllara göre değişimi. Kocaeli Med J. 2018;7(1):32-6. https://doi.org/10.5505/ktd.2018.94824

12. Özel $Y$, Büyükzengin $K B$, Yavuz MT. Klinik örneklerden izole edilen metisiline dirençlive duyarlıStaphylococcus aureus suşlarının antibiyotik direnç profilinin araştırılması. ANKEM Derg. 2017;31(2):41-7. 
13. Rağbetli C, Parlak M, Bayram Y, Guducuoglu H, Ceylan N. Evaluation of antimicrobial resistance in Staphylococcus aureus Isolates by years. Interdiscip Perspect Infect Dis. 2016;2016:9171395. https://doi.org/10.1155/2016/9171395

14. Sievert DM, Ricks $P$, Edwards JR et al. National Healthcare Safety Network (NHSN) Team and Participating NHSN Facilities. Infect Control Hosp Epidemiol. 2013;34(1):1-14. https://doi.org/10.1086/668770

15. Sipahi OR, Uysal S, Aydemir SŞ, et al. Antibacterial resistance patterns and incidence of hospital acquired Staphylococcus aureus bacteremia in a tertiary care educational hospital in Turkey:a perspective from 2001 to 2013. Turk J Med Sci. 2017;47(4):1210-5. https://doi.org/10.3906/sag-1607-63

16. Song JH, Hsueh PR, Chung DR et al. ANSORP Study Group. Spread of methicillin-resistant Staphylococcus aureus between the community and the hospitals in Asian countries: an ANSORP study. J Antimicrob Chemother. 2011;66(5):1061-9. https://doi.org/10.1093/jac/dkr024

17. Şen $P$, Demirdal $T$, Özdemir R, et al. Antimicrobial resistance in Staphylococci: a 6-year-evaluation. Medeniyet Medical Journal. 2017;32(4):205-11. https://doi.org/10.5222/MMJ.2017.205

18. Şirin MC, Ağuş N, Yılmaz N, et al. Klinik örneklerden izole edilen Staphylococcus aureus suşlarinda antibiyotik direnci. Journal of Clinical and Analytical Medicine. 2015;6(Suppl 6):859-63.

19. Tekin A, Dal T, Deveci Ö, et al. In vitro susceptibility to methicillin, vancomycin and linezolid of staphylococci isolated from bloodstream infections in eastern Turkey. Braz J Microbiol. 2014;45(3):829-33.
https://doi.org/10.1590/S1517-83822014000300010

20. Telli M, Okulu Y, Patı Y. Staphylococcus aureus Suşlarında metisiline direnç oranındaki değişim: metisiline direnç azalıyor mu? ANKEM Derg. 2018;32(3):103-8.

21. The European Committee on Antimicrobial Susceptibility Testing. New definitions of S, I and R. http://www.eucast.org/newsiandr/ (erişim tarihi: 12.04.2019)

22. The European Committee on Antimicrobial Susceptibility Testing. Resistance mechanisms. http://www.eucast.org/resistance_mechanisms/

23. Ulusal Antimikrobiyal Direnç Surveyans Sistemi, Türkiye Halk Sağlığı Kurumu, Sağlık Bakanlığı Ankara. http://uamdss.thsk.gov.tr

24. Yıldız Ö, Çoban AY, Şener AG, et al. Antimicrobial susceptibility and resistance mechanisms of methicillin resistant Staphylococcus aureus isolated from 12 Hospitals in Turkey, Ann Clin Microbiol Antimicrob. 2014;13:44. https://doi.org/10.1186/s12941-014-0044-2

25. Yılmaz EŞ, Aslantaş Ö. Antimicrobial resistance and underlying mechanisms in Staphylococcus aureus isolates. Asian Pac J Trop Med. 2017;10(11):1059-64. https://doi.org/10.1016/j.apjtm.2017.10.003

26. Yüksekkaya Ş, Opuş A, Güvenç Hi, et al. 2009-2013 yılları arasında Konya Eğitim ve Araştırma Hastanesi'nde kan kültüründen izole edilen Staphylococcus aureus suşlarının antimikrobiyal ajanlara duyarlılıklarının değerlendirilmesi. ANKEM Derg. 2017;31(1):1-6.

27. Zencir M, Arı A, Yılmaz N, et al. Metisiline dirençli Staphylococcus aureus suşlarının antibiyotiklere duyarlıı̆ı̆, hastaların klinik özellikleri ve mortaliteyi etkileyen faktörler. ANKEM Derg. 2016;30(1):18-23. 